University of Nebraska - Lincoln

DigitalCommons@University of Nebraska - Lincoln

U.S. Environmental Protection Agency Papers

U.S. Environmental Protection Agency

2007

Science, Scientists, and Policy Advocacy

Robert T. Lackey

U.S. Environmental Protection Agency, lackey.robert@epa.gov

Follow this and additional works at: https://digitalcommons.unl.edu/usepapapers

Lackey, Robert T., "Science, Scientists, and Policy Advocacy" (2007). U.S. Environmental Protection Agency Papers. 142.

https://digitalcommons.unl.edu/usepapapers/142

This Article is brought to you for free and open access by the U.S. Environmental Protection Agency at DigitalCommons@University of Nebraska - Lincoln. It has been accepted for inclusion in U.S. Environmental Protection Agency Papers by an authorized administrator of DigitalCommons@University of Nebraska - Lincoln. 


\title{
Science, Scientists, and Policy Advocacy
}

\author{
ROBERT T. LACKEY
}

National Health and Environmental Effects Research Laboratory, U.S. Environmental Protection Agency, Corvallis, OR 97333, U.S.A., email lackey.robert@epa.gov

\section{Introduction}

I am concerned that we scientists in conservation biology, ecology, natural resources, environmental science, and similar disciplines are collectively slipping into a morass that risks marginalizing the contribution of science to public policy. Advocating personal positions on ecological policy issues has become widely tolerated as acceptable professional behavior and is even encouraged by a substantial fraction of the scientific community (Marris 2006; Scott et al. 2007). Scientists are uniquely qualified to participate in public policy deliberations and they should, but advocating for their policy preferences is not appropriate.

Despite an extensive debate in the literature on the proper role of science and scientists in policy deliberations, points of general agreement and specific differences often get lost amid the semantic confusion caused by inconsistent definitions for key words or concepts (Trudgill 2001). Table 1 provides the precise definitions I have used throughout this essay.

Those of us who provide scientific information to decision makers and the public should strive to be more vigilant, precise, demanding, and rigorous in distinguishing between policy-neutral and policy-inculcated scientific information. Science is only one element of the complex deliberations over major ecological policy questions that take place in a democracy, but science is critical, and scientists can and do play an important role (Sarewitz 2004; Lackey 2006).

My unequivocal overall view on the role of scientists in ecological policy and management is, first, that scientists should contribute to the policy process. This is not only the right thing to do, but we are also obligated to do so, especially if our work is funded by public resources. I do not hold with the notion that it is sufficient for scientists to publish their findings solely as scholarly papers. The assertion that scientists should be involved in providing and explaining the underlying science to help resolve important policy questions is, for me, a given.

Second, when scientists contribute to policy analysis and implementation, they must exercise great care to play an appropriate and clearly defined role. The interface between science and policy can be bewildering for many of us who develop, provide, or interpret scientific information. Working at the interface is also where many of us mislead or confuse decision makers and the public because we let our personal policy preferences color our science.

The formidable challenge of developing and providing technical and scientific information to inform policy deliberations in an objective and relevant way is not unique to ecological fields (Rykiel 2001). Whether one is working as a stock analyst in the research unit of a brokerage firm (Boni \& Womack 2003), a medical expert testifying in malpractice trials (Caldwell 2005), a funding officer at an international development agency that might finance a proposed shrimp-farming operation (Béné 2005), or an intelligence analyst within a government national security agency (Armstrong 2002), the job of providing accurate, relevant, and policy-neutral information is always a challenge.

\section{Policy Context}

Most of today's ecological policy issues are politically contentious, socially wrenching, and replete with scientific uncertainty (Pielke 2004; Robinson 2006). Examples include reversing the decline of salmon in western North America; deciding on the proper role of logging on public lands; ameliorating the effects of human-caused climate change; avoiding the extinction of species; and making sense of the confusing policy choices surrounding notions of sustainability.

Paper submitted August 16, 2006; revised manuscript accepted September 28, 2006.

12

Conservation Biology Volume 21, No. 1, 12-17

(C)2007 Society for Conservation Biology

No claim to US government works

DOI: 10.1111/j.1523-1739.2006.00639.x 
Table 1. Definitions of keywords used in this essay.

Normative science: science developed, presented, or interpreted based on an assumed, usually unstated, preference for a particular policy or class of policy choices.

Policy: a decision or plan of action for accomplishing a desired outcome.

Policy analysis: formal assessment of the consequences and implications of the possible options for addressing a policy problem.

Policy advocacy: active, covert, or inadvertent support of a particular policy or class of policies.

Politics: process of debate, negotiation, and compromise for achieving a desired policy goal.

Preference: the preferred option from among a set of policy choices or alternatives.

Science: information gathered in a rational, systematic, testable, and reproducible manner.

Scientist: a person who generates or interprets scientific information or science.

Value: a core belief that tends to determine or shape personal or group policy preferences.

Ecological policy issues are inherently complex and are often described by political scientists as being "wicked" and "messy" (Salwasser 2004). All these issues share several qualities: (1) complexity (they have multiple options and trade-offs); (2) polarization (clashes between competing values are routine); (3) winners and losers (for each policy choice, some interests will clearly benefit, some will be harmed, and the consequences for others are uncertain); (4) delayed consequences (the policy options often provide no immediate "fix" and the benefits, if any, of painful concessions may not be evident for decades); (5) decision distortion (advocates often appeal to strongly held values and distort or hide the real policy choices and their consequences); (6) national versus regional conflict (national priorities often differ substantially from those at the local or regional level); and (7) misuse of scientific information (science can end up an inappropriate battleground because arguments over science are often actually a surrogate venue for arguments over values and preferences) (Lackey 2006). As if ecological policy issues were not muddled enough, they often become further clouded by skepticism about the motivation of scientists and the accuracy of the scientific information they provide (Mills 2000; Pielke 2004). Most science is funded by government agencies, businesses and corporations, and myriad public and private interest and advocacy groups (Sarewitz 2004). Each arguably has a vested interest in the outcome of the debate and often promulgates "science" that appears to support its favored position (Doremus 2005).

\section{Science and Scientists}

What is the appropriate role for scientists in policy making? Our role is not described adequately under the current and simplistic rubric of providing the best available science or good science (Doremus \& Tarlock 2005; Sullivan et al. 2006). Furthermore, scientists are often asked to contribute scientific information in the midst of clashing values, differing preferences, and opposing, often mutually exclusive, societal priorities (Lach et al. 2003; Pielke 2004). The public and bureaucratic discourse surround- ing wicked, messy ecological policy issues is not for the psychologically sensitive, those with thin skins, or anyone with an aversion to being challenged scientifically or professionally (Lackey 2006). Regardless of the reasons, many scientists are reluctant to contribute beyond publishing their scientific contributions in scholarly journals (Lach et al. 2003).

One common concern about the science-policy interface is that some so-called science is imbued with policy preferences (Trudgill 2001). Such science is labeled as normative and its use is potentially an insidious kind of scientific corruption (Lackey 2004). What separates normative science from "regular" science is that normative science is developed, presented, or interpreted based on a tacit, usually unstated, preference for a particular policy or class of policy choices. Normative science often is not perceptibly normative to policy makers or even to many scientists. The use of such science by scientists, however, is stealth policy advocacy even if its use is not intentional. As is argued by postmodernists, because all science is socially constructed, science is value driven and is, therefore, normative. My discomfort, however, is not with the notion that science is a human enterprise and therefore reflects the values of the participants, but with science influenced by policy preferences.

Attempting to be both the provider of policy-neutral science and an advocate for one's personal policy preferences is laden with conflicts of interest and, if not carefully communicated, is potentially unethical (Mills 2000). The same types of conflicts are present when one organizational unit attempts to serve as both the provider of science and the regulator or manager of environmental or natural resource (Sullivan et al. 2006). In government bureaucracies it is an old and ongoing challenge to keep the research and/or science enterprise independent and policy neutral rather than manipulating it to help sell or defend the agency's policy decisions (Cohn 2005; Doremus 2005).

Many writers who muse over the proper role of science in ecological policy concentrate on the philosophical notion of positivism and the fact-value distinction (Roebuck \& Phifer 1999). I subscribe to the view that science is not free of values. It is, after all, a human enterprise, but this fact does not make all science normative (Odenbaugh 
2003). Policy-neutral science strives to describe the world accurately and is characterized by transparency, reproducibility, and independence.

Using the terminology of philosophy, but without becoming mired in the nuances of philosophical analysis, consider the simple but fundamental difference between is (i.e., fact) and ought (i.e., preference) statements. Science deals with the "is" world (facts about the past, present, or future). For example, consider the distribution of a hypothetical bird found only in a limited geographic area and with an overall population level that appears to be declining at 5\% per year. Such an observation (the decline) is a scientific "is" statement. Whether this fact documenting the population decline is something that warrants a change in policy would be an "ought" statement-a policy question. The policy world deals legitimately and appropriately with the oughts and shoulds (i.e., preferences): Should the decline of the bird population be reversed? Science is restrained to statements of is: The population is declining at $5 \%$ per year.

A current example that vividly illustrates the is/ought dichotomy is the case of declining salmon populations in the Pacific Northwest (U.S.A.). Many dams have a measurable effect on these populations. One oft-debated policy option to help restore salmon runs is to remove or breach dams. It is common for scientists to be asked to gauge the likely effects of removing, or preserving, a particular dam or set of dams-a legitimate and appropriate role for scientists. There is, however, no scientific imperative to remove, or maintain, any dam for any ecological reason, including salmon recovery. All of the policy options would have ecological consequences, some of which may even be catastrophic from a salmon perspective, but ecological consequences are simply one element that the public and decision makers must weigh in choosing from a set of options. Understanding the likely ecological outcomes of each choice is what the public and decision makers need from scientists as they weigh policy alternatives. They do not need personal opinions from scientists on which policy option ought to be chosen.

How should scientists explain to the public and decision makers the relevant scientific information pertaining to the likely effects of dam construction or removal? There are obviously many ecological changes that will take place when a dam is removed but what words should be used to describe those changes? What point of ecological reference should be used, if any? Should benchmarks of any kind be used?

Often I hear or read in scientific discourse words such as degradation, improvement, good, and poor. Such value-laden words should not be used to convey scientific information because they imply a preferred ecological state, a desired condition, a benchmark, or a preferred class of policy options. Doing so is not science, it is policy advocacy. Subtle, perhaps unintentional, but it is still policy advocacy. An argument is sometimes made that such terms as degradation, good, and healthy can be used in scientific reports if the terms are clearly defined, measured, and monitored. Why use them unless you are conveying the impression that one particular condition is preferred policy wise? A forest that has been clearcut is $d e$ graded habitat from the perspective of Spotted Owls and red tree voles, but it is improved habitat from the perspective of other species such as White-crowned Sparrows and black-tailed deer. The science is exactly the same, only the policy context differs. The appropriate science words are, for example, change, increase, or decrease. These words describe the scientific information in ways that are usually considered policy neutral. In short they convey no policy preference and convey science in a policy-neutral manner. Be clear, be candid, be brutally frank, but be policy neutral when providing science to the public, policy makers, and others.

Scientists have a responsibility to correct misinterpretations of science, especially if it is being conveyed in ways that imply support for particular policies. Even though scientific information alone does not carry a policy imperative, making sure that policy advocates and policy makers understand and use scientific information accurately and honestly is essential (Doremus \& Tarlock 2005). Some scientists believe that not speaking up when science is being misinterpreted or misused in policy deliberations is tantamount to dereliction of duty (Karr 2006). Conversely, scientists have an obligation to avoid conveying overtly or covertly any policy preference. Using normative science is a case of covertly advocating a policy preference. Among some conservation biologists, ecologists, and those from similar professional disciplines, the implicit policy preference is assumed to be that ecosystems unaltered by humans are inherently good, or at least preferable to ecosystems altered by humans (van Houtan 2006). Unstated, but implied, is that the less altered an ecosystem the better. But science leads to no preferred state or to any inherently good condition. In short, there is no scientific imperative for adopting any policy option (McCoy \& Atwood 2005).

There is no universally accepted list of implicit policy preferences that is typically imbedded within normative science in ecological and environmental disciples. The following policy preferences are common: human-caused extinctions are inherently bad and should be avoided; unaltered ecosystems are preferable to altered; reducing complexity in ecosystems is undesirable; natural evolution is good, human intervention is not; more biological diversity is preferable to less biodiversity; and native or indigenous species are preferable to non-native species. These examples (and their converses) are each valid policy preferences, but not one is a scientific imperative (Matsuda 1997).

How widespread is normative science in disciplines such as conservation biology, ecology, fisheries, wildlife, and forestry? In my experience with a number of different 
ecological policy issues, normative science is frequent. I often observe biological diversity or ecological integrity calculated solely on the number of native species. Except for someone doing truly basic, independent, or nonapplied research, the decision to include, or exclude, exotic or non-native species in biodiversity calculations is a policy choice and not a choice for scientists to make. That is not to say the native species and exotic species are interchangeable; they are not, but neither native species nor exotic species are inherently preferable in a scientific sense.

Some scientific societies and other professional organizations assert that biological diversity is inherently good. Understanding the role of biological diversity may be important to explaining ecosystem structure and function and even essential for sorting out evolutionary processes, but a value judgment must be invoked to define certain levels of biological diversity as inherently good or that increasing biodiversity is preferable, policy wise, to decreasing biodiversity (Meine et al. 2006). Such a value judgment reflects a specific policy preference, but there are competing policy preferences that are also valid. Furthermore, how should those scientific and professional societies that promulgate explicit ecological policy preferences promote those preferences? Should their journals only publish papers that accept their policy preferences? Should the society accept advertising that does not explicitly support their stated policy positions? Is it realistic to expect outsiders to accept science published in their journals as being policy neutral? Once policy preferences are rooted in the core of the scientific enterprise, it is not clear to me how scientific independence and credibility can survive over the long term.

Another example of the inappropriate blending of science and policy preference is the application of the metaphor of ecosystem health-a common, even pervasive, use of normative science (Lackey 2003). To most proponents of ecosystem health, the alluring feature of the human health metaphor is that people have an inherent understanding of personal health. We each have an idea of what constitutes a healthy person in contrast to a sick person. By extension most people envision instinctively a healthy ecosystem as being pristine or at least appearing to be minimally altered by human action (e.g., a primordial forest, a wilderness lake, or perhaps a pastoral landscape). Thus, it is often argued that ecosystem health is intuitively grasped by the general public, policy officials, and scientists.

Applying the notion of human health to ecosystems provides a simple paradigm for viewing ecological policy questions. By implication, adopting the metaphor also defines what type of information (i.e., scientific) is necessary to help decision makers (Lackey 2003). When I am sick, I seek the technical expertise of a medical practitioner. Therefore, applying the same metaphor, when an ecosystem is sick it follows that an ecosystem health professional ought to be consulted. Ecosystem health is a value-driven policy construct. Yet often it is passed off as science to unsuspecting policy makers and the public.

Who decides what is the preferred state of an ecosystem? Arguably there is a consensus that a healthy human is preferable to a sick one, but what is the analog for ecosystems? Sometimes and in acknowledgment of the intellectual weakness of the notion of ecosystem health, scientists assume a preferred state but hide behind a cloak of scholarly precision with statements such as "We used a precise definition of ecosystem health to analyze the ecosystem, but others misused or misinterpreted the results." and "We cannot be responsible for how others use the results." True, but why use the metaphor if people are likely to misuse the scientific information?

Think what the average recipient of scientific information actually hears when data or assessments are packaged or presented under the rubric of ecosystem health. As with humans, healthy is good. The opposite condition must be unhealthy, which is surely undesirable in ecosystems as it is in humans. Is this a fair way to describe policy alternatives? One person's damaged ecosystem is another person's improved ecosystem. A healthy ecosystem can be either a malaria-infested swamp or the same land converted to an intensively managed rice paddy. Neither condition can be seen as healthy except through the lens of an individual's values and policy preferences (Freyfogle \& Newton 2002).

Should a healthy ecosystem be defined as the ecological state that existed a 1000 years ago, just prior to 1492 , or at the end of last week? The answer is a value judgment, a policy choice, perhaps the product of political deliberations, but it is not solely a scientific decision (Hunter 1996). Scientists can and should assess the ecological consequences of adopting each possible policy or management goal (i.e., various alternative definitions of "healthy" ecosystem), but the choice of which state of the ecosystem is the desired goal is a societal one (Rykiel 2001).

Politically, from what I observe, the use of normative science cuts across the ideological spectrum. It seems no less common coming from the political Left or Right, from the Greens or the Libertarians. Regardless of the virtue of the policy preference, normative science is a corruption of science.

Fair or not, it is true that some scientists, at least as perceived by many people, appear to operate as policy advocates, not as unimpeachable providers of policy-neutral information. They are observed, for example, publicly arguing for, or against, the Kyoto Protocol, the Convention on Biological Diversity, legislation to protect marine resources, or a controversial housing development. In my own area of research, for example, many scientists sign petitions to remove, or preserve, a particular salmonkilling dam for reasons that sound like science, read like science, are presented by people who cloak themselves in the accouterments of science but who are actually 
offering nothing but policy advocacy masquerading as science.

\section{Conclusion}

We must achieve within ecological and natural resource professions a clear understanding of the distinctions between science and policy and an understanding of the appropriate roles and responsibilities of science, scientists, and policy advocacy. So, what specifically should a vigilant scientist do to assure that the proper roles of science, scientists, and policy makers are understood and followed? First, be sensitive to the boundary between scientific or technical issues and value judgments. The boundary between policy neutrality and policy advocacy may not always be a bright line, but be especially vigilant when the line becomes dim.

Second, when the major points of dissention in a policy debate are over values and preferences (the usual case), try to exhort decision makers to focus on these often fractious elements of the decision making process rather than the technical and scientific aspects. Debates of questions of science often end up serving as a surrogate polemic for the inability (or unwillingness) of decision makers to adjudicate unpleasant value and preference trade-offs. Do not fall into the trap of substituting debate over scientific information and interpretation of data for debate over which values and preferences will carry the day.

Third, be brutally honest with decision makers about the technical feasibility of each possible policy option and the uncertainties associated with the resulting ecological consequences. Often, the most useful input scientists can provide is to identify the estimated probability of success (for achieving the stated policy goal) for each of the various competing policy options.

Many of today's ecological policy issues are contentious, socially divisive, and full of conundrums. They are, however, typical of those that professional ecologists will confront for the foreseeable future. Those of us who provide information to help inform the participants involved in ecological policy debates must be cognizant of and appreciate the importance of scientific information, but in a democracy we also must recognize the reality that scientific information is just one element in complex political deliberations.

To policy makers, I say be alert. Call our hand when you observe us overstepping our role as scientists and slipping into stealth policy advocacy. Scientific information is too important to the resolution of vital, divisive, and controversial ecological issues to allow some scientists to marginalize science through its misuse. Do not allow the overzealous among us to corrupt the entire science enterprise.
To scientists, I say get involved, but play the appropriate role. If you choose to advocate your personal policy preferences, make it clear to everyone involved that you have stepped out of a scientific role and into the role of policy advocate. In playing the role of policy advocate, be aware that your values and preferences inherently are no more (or less) important than other participants in the policy debate. To do otherwise is to corrupt both the political process and scientific enterprise.

\section{Acknowledgments}

Over my career in government, academia, and the private sector, many colleagues helped shape my current views about the proper role of science and scientists in ecological policy. Several colleagues reviewed versions of this essay. Particularly helpful were the suggestions provided by K. I. Ashley, M. Bagdovitz, L. L. Bailey, S. M. Bartell, G. A. Bisbal, G. W. Boehlert, R. D. Cardwell, T. H. DeWitt, S. L. Duncan, J. M. Emlen, A. K. Fitzsimmons, E. T. Freyfogle, S. J. Grabowski, M. Healey, G. M. Hidy, M. L. Hunter, J. Hurley, G. Ice, S. J. Jordan, P. L. Kennedy, E. E. Knudsen, D. H. Lach, J. J. Lawler, D. F. Markle, B. M. Matsuda, A. G. Maule, J. H. Michael, A. T. Morzillo, D. L. Noakes, R. A. Pielke Jr., C. E. Peterson, D. Poon, J. H. Power, J. L. Rachlow, H. A. Regier, R. B. Rettig, H. J. Salwasser, J. R. Scarce, J. M. Scott, C. L. Smith, B. B. Stout, A. J. Talbot, N. S. Urquhart, R. L. Vadas Jr., and D. White. Some of these reviewers maintain different views than those expressed in this essay; thus, being acknowledged as a reviewer does not constitute an endorsement. The opinions and views expressed do not necessarily represent those of any organization.

\section{Literature Cited}

Armstrong, F. T. 2002. Ways to make analysis relevant but not prescriptive. Studies in Intelligence 46:37-43.

Béné, C. 2005. The good, the bad, and the ugly: discourse, policy controversies, and the role of science in the politics of shrimp farming development. Development Policy Review 23:585-614.

Boni, L., and K. L. Womack. 2003. Wall Street research: will new rules change its usefulness? Financial Analysts Journal 59:25-29.

Caldwell, P. 2005. Courting the expert: clash of culture? British Journal of Haematology 129:730-733.

Cohn, J. P. 2005. After the divorce: improving science at federal wildlife agencies. BioScience 55:10-14.

Doremus, H. 2005. Science plays defense: natural resource management in the Bush Administration. Ecology Law Quarterly 32:249306

Doremus, H., and A. D. Tarlock. 2005. Science, judgment, and controversy in natural resource regulation. Public Land and Resources Law Review 26:1-37.

Freyfogle, E. T., and J. L. Newton. 2002. Putting science in its place. Conservation Biology 16:863-873.

Hunter, M. L. 1996. Benchmarks for managing ecosystems: are human activities natural? Conservation Biology 10:695-697.

Karr, J. R. 2006. When government ignores science, scientists should speak up. BioScience 56:287-288. 
Lach, D. L., P. C. List, B. S. Steel, and B. A. Schindler. 2003. Advocacy and credibility of ecological scientists in resource decision making: a regional study. BioScience 53:170-178.

Lackey, R. T. 2003. Appropriate use of ecosystem health and normative science in ecological policy. Pages $175-186$ in D. J. Rapport, W. L. Lasley, D. E. Rolston, N. O. Nielsen, C. O. Qualset, and A. B. Damania, editors. Managing for healthy ecosystems. Lewis Publishers, Boca Raton, Florida.

Lackey, R. T. 2004. Normative science. Fisheries 29:38-39.

Lackey, R. T. 2006. Axioms of ecological policy. Fisheries 31:286-290.

Marris, E. 2006. Should conservation biologists push policies? Nature 442:13.

Matsuda, B. M. 1997. Conservation biology, values, and advocacy. Conservation Biology 11:1449-1450.

McCoy, N. H., and S. Atwood. 2005. Flaws in Orr's laws (and the paradigm that produced them): an abbreviated response. Conservation Biology 19:1318-1320.

Meine, C., M. Soule, and R. Noss. 2006. "A mission-driven discipline": the growth of conservation biology. Conservation Biology 20:631651.

Mills, T. J. 2000. Position advocacy by scientists risks scientific credibility and may be unethical. Northwest Science 74:165-167.

Odenbaugh, J. 2003. Values, advocacy, and conservation biology. Environmental Values 12:55-69.

Pielke, R. A. Jr. 2004. When scientists politicize science: making sense of controversy over The Skeptical Environmentalist. Environmental Science and Policy 7:405-417.
Robinson, J. G. 2006. Conservation biology and real-world conservation. Conservation Biology 20:658-669.

Roebuck, P., and P. Phifer. 1999. The persistence of positivism in conservation biology. Conservation Biology 13:444-446.

Rykiel, E. J. 2001. Scientific objectivity, value systems, and policy making. BioScience 51:433-436.

Salwasser, H. 2004. Confronting the implications of wicked problems: changes needed in Sierra Nevada National Forest planning and problem solving. Pages 7-22 in Proceedings of the Sierra Nevada science symposium: science for management and conservation. General technical report PSW-GTR-193. U.S. Department of Agriculture Forest Service, Kings Beach, California.

Sarewitz, D. 2004. How science makes environmental controversies worse. Environmental Science and Policy 7:385-403.

Scott, J. M., J. L. Rachlow, R. T. Lackey, A. B. Pidgorna, J. L. Aycrigg, G. R. Feldman, L. K. Svancara, D. A. Rupp, and D. I. Stanish. 2007. Policy advocacy in science: prevalence, perspectives, and implications for conservation biologists. Conservation Biology 21:29-35.

Sullivan, P. J., et al. 2006. Defining and implementing best available science for fisheries and environmental science, policy, and management. Fisheries 31:460-465.

Trudgill, S. T. 2001. Psychobiogeography: meanings of nature and motivations for a democratized conservation ethic. Journal of Biogeography 28:677-698.

van Houtan, K. S. 2006. Conservation as virtue: a scientific and social process for conservation ethics. Conservation Biology 20:13671372.

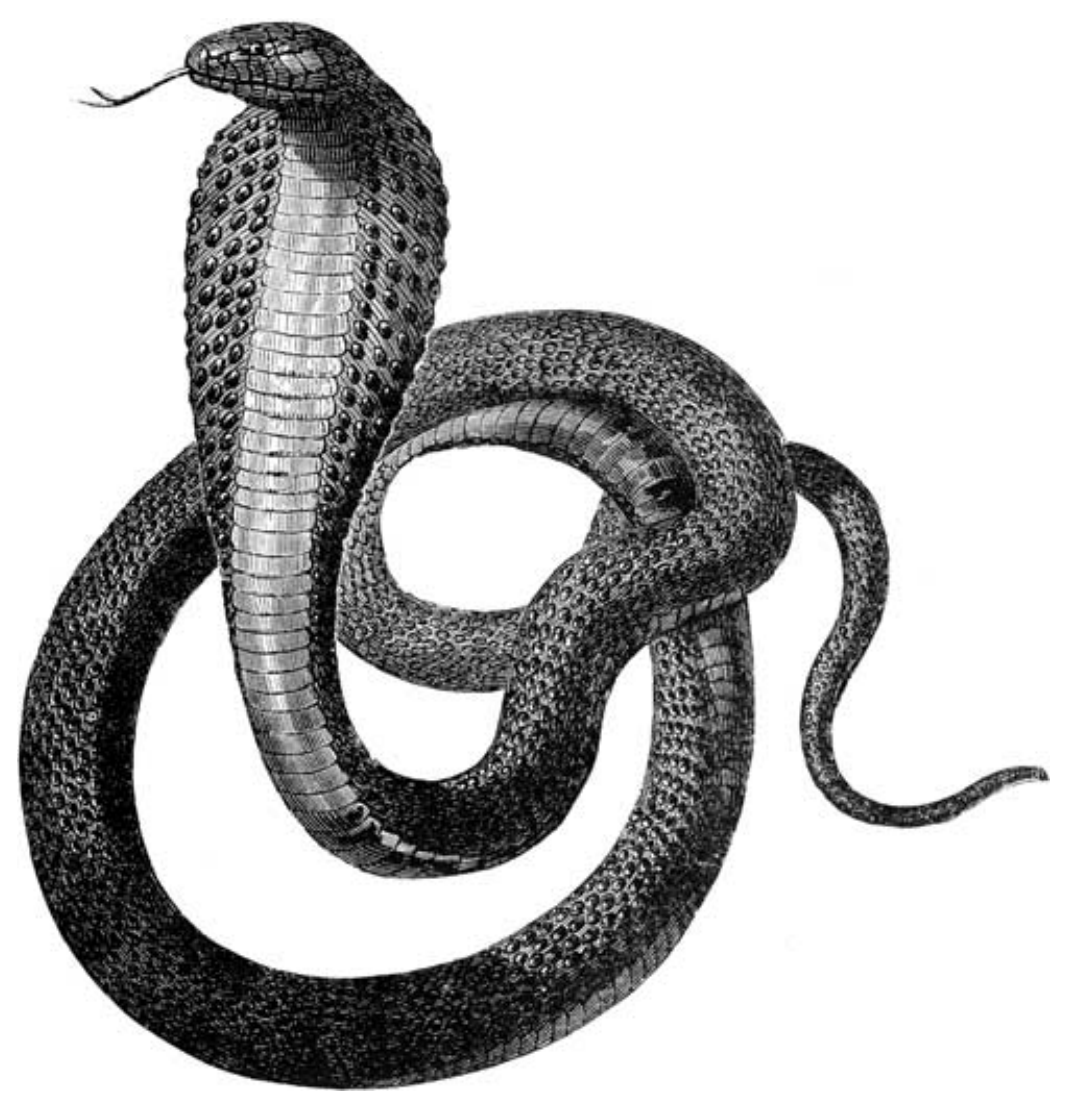

